\title{
Between Transition from IPv4 and IPv6 Adaption: The Case of Jordanian Government
}

\author{
Iman Akour \\ Management Information Systems Department \\ University of Sharjah \\ Sharjah, UAE
}

\begin{abstract}
IPv6 is being the new replacement for its predecessor IPv4, IPv6 has been used by most Internet services and adopted by most internet architecture these days. Existing protocol IPv4 reveals critical issues such as approaching exhaustion of its address space, continuous growth of the internet and rising new technologies lead to increasing the complexity of the configuration, etc. To healing from the limitations of IPv4 Internet Engineering Task Force (IETF) developed the next generation IP called IPv6. Jordan, like many other countries, is endeavoring to adapt and transit from IPv4 to in an efficient way that will provide an excellent level of service as coveted by its citizens. In this study, the author tried to navigate IPv6 concept from the literature and review the thoughts, steps, and challenges that the Jordanian government pursued in transiting from IPv4 to IPv6.
\end{abstract}

Keywords-IP networks; IPv6 protocol; IPv6 road map; ipv6 transition; IPv6 adoption

\section{INTRODUCTION}

Since 1999, the IPv6 is a fact, it isn't a theory anymore. IPv6 forum has appeared as a result of joint efforts of more than 65 companies/organizations worldwide. The main objective of the IPv6 forum is to promote the IPv6 protocol and to educate the market on its benefits and advantages and to deploy its use worldwide. The appearance of IPv6 protocol coincided with the emergence of the document that outlined the IPv6 specification, but unfortunately, even with the exhaustion of IPv4 looming, the extent of IPv6 adoption remains low [1].

Now is the right time for deploying the IPv6 globally, because the IPv4 addresses are becoming rare. There are a lot of efforts around the world to increase broadband penetration; the greater number of smart phones and network-ready devices are entering the market, and the number of Internet users is growing steadily. It is necessary to supply larger number of global IP addresses than the IPv4 pool can to maintain the sustainable, long-term development of an extensive and open Internet.

Worldwide deployment of the IPv6 is vital to the continuous growth and stability of the Internet. Government, business, and technical fields have been cooperating and getting ready to adopt IPv6 since it fulfills the growth of addressing requirements.

Many countries in North America, Caribbean, Latin America, European Union, Middle East, Asia Pacific, and Africa have committed to IPv6 deployment within prescribed timelines, and many of them have established Task Forces, bringing together stakeholders from the public and private sectors [2].

In this paper, the author's aim is to define IPV6, its stages, identifies its benefits, challenges, Jordan's position compared it other countries in their Internet Protocol usage, as well as the challenges facing the roll out of IPv6 in Jordan.

The author attempt to investigate the status of spreading and using IPv6 in Jordan from telecommunication perspective and customer's intention. Three main hypotheses are formulated and addressed based on three main factors that could have an impact on spreading and moving to IPv6 (i.e., educational qualification, gender, and place of residence).

The study is organized as follows: Section 2 illustrates the readiness of IPv6 in Jordan. Section 3 provides the preliminary investigation which was performed to survey the research area, hypotheses and sampling study. Result and discussion are presented in section 4 . The study is concluded in section 5 .

\section{IPV6 READINESS IN JORDAN}

There are many studies in the literature that offer valuable data on the IPv6 adoption process from various perspectives. Jakub Czyz et al. [3] divided the stakeholders into three types: Internet content providers, service providers, and content consumers. They mentioned that these three categories encapsulate the key perspectives should be considered to realistically assess deployment. They found that the regional adoption is not uniform compared to IPv4. Moreover, it was clear that over the last three years, the nature of IPv6 utilization-in terms of traffic, content, reliance on transition technology, and performance-has shifted dramatically from prior findings, indicating a maturing of the protocol into production mode.

One of the important issues must be explored is the migration from IPv4 to IPv6 in Jordan. IPv4 is installed in almost all the companies Internet infrastructures. Therefore, the transition process from IPv4 to IPv6 is challenging and expensive.

Even though several techniques were introduced to avoid the transition or even to postpone it like CIDR, dual stack, tunneling and NAT, the pool of IPv4 addresses is depleting and the only solution is to move towards IPv6 [4].

The collaborative applications on Internet protocol version 4 faced many problems. For instance, there were many 
difficulties in MSN Messenger implementation to get it operates with NAT or other IPv6 alternative solutions. Due to this fact, IPv6 has been designed to support both real-time and multimedia applications. Another example of such applications is collaborative gaming which needs a good QoS, because they require the use of audio and video. Some of Microsoft Window versions support IPv6 with the intention of developing complex real-time multiplayer games, VoIP, and IP television [5].

Organizations have to decide whether is it the right time to change or not now. The change is associated with cost and time. If hardware infrastructure does not support the IPv6 then it will have to be replaced. Also, it is necessary to upgrade the software. So, such change requires a transition plan. However, this study looks at the issues that are relevant to a decision to be made towards IPv6 adoption in Jordan.

Figure 1 shows the cumulative IPv6 and assignments in Jordan. It can be seen how the number of new assignments is getting lower in comparison for 2013 and 2014.

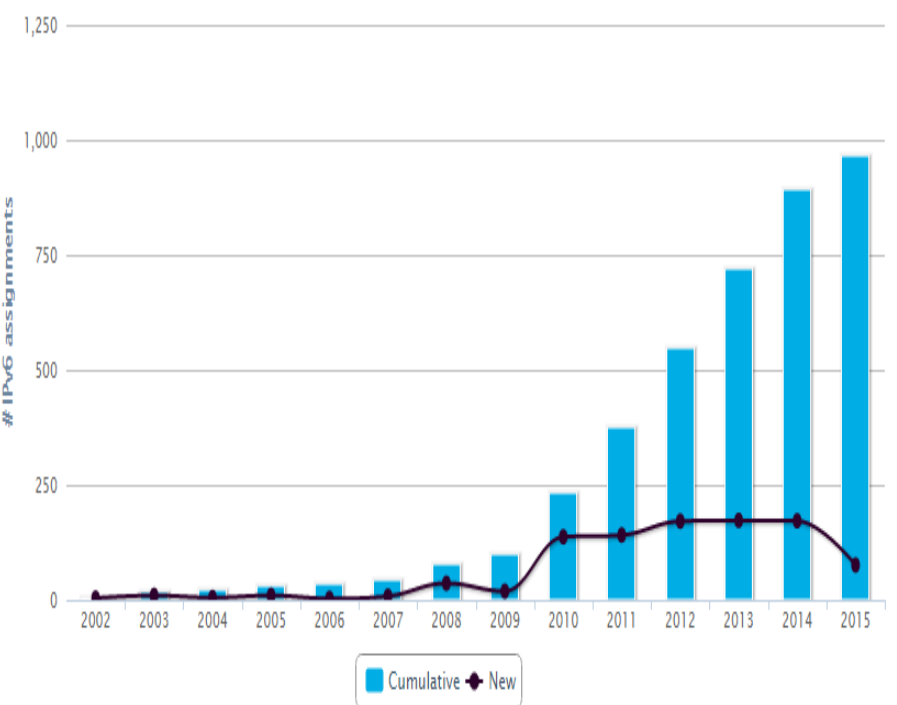

Fig. 1. IPv6 assignments in Jordan 2015 [6]

According to IPv6 test [9] report on August 2015, there is 25 internet service providers for IPv6 in Jordan. They expect a slow growth towards 50\% IPv4 / 50\% IPv6. The report shows the percentage of browsers that default to IPv6 vs. IPv4 when visiting the ipv6-test connection test. Based on the resulted percentage, hopefully, in the distant future, the IPv6 part will grow taller than the IPv4 one. Finally, the report reveals the percentage of browsers that default to IPv6 vs. IPv4 for users that have both v4 and v6 connectivity. Usually, a system will default to v6 when it's available, but in some cases with tunneled connections, v4 stays the default.

\section{PRELIMINARY INVESTIGATION}

To the best of my knowledge, this investigation never been carried out in Jordan. The study intended to explore the perception of Jordanians toward major issues related to IPv6 by exploring the attitudes of diverse group: IT and telecommunication universities student, telecommunication firms and computer centers employees and developers. The main objectives of the study are:

1) To address the level of the existing knowledge about IPv6 within the Jordanian society.

2) To explore whether Jordanians are aware of the benefits and the challenges of utilizing IPv6.

3) To navigate the impact of three main factors that could influence recognizing and moving to IPv6 (gender, educational qualification, and place of residence).

\section{B. Research Hypotheses}

For the purpose of addressing to which extends the knowledge, usage of the IPv6 exists in Jordan, three main Hypotheses are formulated.

1) There are statistically significant differences from the gender perspective in the level of knowledge and usage of IPv6 in the Hashemite Kingdom of Jordan.

2) There are statistically significant differences from educational qualification perspective in the level of knowledge and usage of IPv6 in the Hashemite Kingdom of Jordan.

3) There are statistically significant differences from the place of residence perspective in the level of knowledge and usage of IPv6 in the Hashemite Kingdom of Jordan.

\section{Sampling description and Designed Survey}

The population of this research study is Jordanian Internet specialist users and developers to control the bias of internet knowledgeable and not knowledgeable users. The study utilized a systematic random sampling of internet specialist users from three institutions: the Jordanian Ministry of Information and Communication Technology (MOICT), National Information Technology Center (NITC), Yarmouk University, Hashemite University, and Albalqa Applied University.

The purpose of using several institutes from different places is to control the main three factors the study is addressing (i.e., gender, educational qualification, and place of residence). The surveys distribution and collection were administered by graduate students at Yatmouk University. As a total of 320 surveys were distributed among the above mentioned institutions. The participation in this study was voluntary, a total number of complete surveys is 300 . 
Participants were asked to complete 3 pages survey on their experience and knowledge about IPv6. Likert 5-point scale was employed in this study to determine the participants answers of questions (i.e. Strongly agree, Agree, Neutral, Do not agree, and Strongly not agree). Table 1 summarizes the participants in the study. The participants are divided into three categories based on the three studied factors.

\section{TABLE I. PARTICIPANT SUMMARIZATION}

\begin{tabular}{|l|l|l|}
\hline Factors & Category & Number \\
\hline \multirow{4}{*}{ Gender } & Male & 48 \\
\cline { 2 - 3 } & Female & 52 \\
\cline { 2 - 3 } & Total & 100 \\
\hline \multirow{4}{*}{ Place of residence } & City & 54 \\
\cline { 2 - 3 } & Village & 46 \\
\cline { 2 - 3 } & Total & 100 \\
\hline \multirow{4}{*}{ Educational } & Diploma & 15 \\
\cline { 2 - 3 } & Bachelor & 45 \\
\cline { 2 - 3 } & Master & 40 \\
\cline { 2 - 3 } & Total & 100 \\
\hline
\end{tabular}

As shown in Table 1 the percentage of male participants is $52 \%$, while the percentage of female participants is $48 \%$. The city participant's percentage was $8 \%$ higher than the village percentage. Finally, it seems most of the participants have bachelor degree.

\section{DATA ANALYSIS AND DISCUSSION}

In order to judge the reliability of the used scales of the questionnaire, Cronbach's alpha methodology was employed [7] to calculate a coefficient of internal consistency. Reliability Coefficients for Current Situation of using the IPv6 in the Hashemite Kingdom of Jordan is $\alpha=0.89 \geq 0.7$, which is a high and acceptable value for the purpose of this study.

To answer the main question of this study, to which extend IPv6 is known and used in Jordan; the arithmetic means and standard deviations were used for all questions that measure the level of using IPv6 in Jordan.

The study adopt the following thresholds to judge the degree of the estimate arithmetic average:

- Arithmetic average (less than 2.33) degrees estimate low.

- Arithmetic average (2.34-6.66) degrees estimate medium.

- Arithmetic average (less than 3.67) degrees estimate high.

Table 2 (in Appendix) summarizes the arithmetic mean of the vertebrae, which measure the level of use of IPv6 in the Hashemite Kingdom of Jordan which ranged between 2.70 and 3.80. The employed questionnaire in this study composed of 30 questions.

TABLE II. RESEARCH QUESTIONAIRE

\begin{tabular}{|c|c|c|c|c|c|}
\hline Number & Question & SMA & $\begin{array}{l}\text { The } \\
\text { standard } \\
\text { deviation }\end{array}$ & class & Grade \\
\hline 1) & Do you know what is the IPv6 & 3.42 & 1.49 & 14 & Medium \\
\hline 2) & Do you think we need to move to IPv6 & 3.70 & 0.96 & 3 & High \\
\hline 3) & Do you think the IPv6 enables you to perform actions/functionalities not offered by IPv4? & 3.61 & 1.01 & 7 & Medium \\
\hline 4) & Do you think by moving to IPv6, IPv4 will be obsolete? & 3.16 & 1.10 & 24 & Medium \\
\hline 5) & Are you ready to start using IPv6? & 3.48 & 0.95 & 10 & Medium \\
\hline 6) & $\begin{array}{l}\text { Is Kingdom of Jordan starts establishing the required infrastructure and architecture for } \\
\text { launching the IPv6? }\end{array}$ & 2.73 & 1.01 & 33 & Medium \\
\hline 7) & Do you believe that Kingdom of Jordan has already IPv6? & 2.89 & 2.89 & 31 & Medium \\
\hline 8) & Do you prefer establishing a test-bed for IPv6? & 3.29 & 3.29 & 22 & Medium \\
\hline 9) & Do you have the necessary skill to develop applications/ sites work on IPv6? & 3.39 & 0.94 & 18 & Medium \\
\hline 10) & Do you believe that IPv6 will cost more that IPv4? & 3.46 & 0.83 & 11 & Medium \\
\hline 11) & Do you think Kingdom of Jordan does not provide IPv6 to ISPs & 3.32 & 0.89 & 20 & Medium \\
\hline 12) & Do you think ISPs play essential roles in not disseminating Ipv6 in Kingdom of Jordan & 3.73 & 0.93 & 2 & High \\
\hline 13) & $\begin{array}{l}\text { Do you thing ISPs in Kingdom of Jordan do not move to IPv6, because the benefit that they } \\
\text { gain from using IPv4 }\end{array}$ & 3.68 & 0.93 & 5 & High \\
\hline 14) & Can you deploy and use websites on IPv6 without ISPs intervention? & 3.07 & 1.04 & 28 & Medium \\
\hline 15) & Do you believe that ISPs in Jordan already have IPv6 and it is working? & 3.20 & 0.92 & 23 & Medium \\
\hline 16) & Do you believe that ISPs in Jordan already have IPv6 but they don't activate it & 3.38 & 0.97 & 19 & Medium \\
\hline 17) & Do you know any institute/s use IPv6? & 2.70 & 0.93 & 34 & Medium \\
\hline 18) & Do you have the willingness to participate in any IPv6 workshops in Kingdom of Jordan? & 3.80 & 1.15 & 11 & High \\
\hline 19) & Can you conduct new services on IPv6 while you are still keep using IPv4 & 3.10 & 0.85 & 27 & Medium \\
\hline 20) & $\begin{array}{l}\text { Do you think the main reason behind not moving to IPv6 yet is the reluctance of Jordanian } \\
\text { firms as it needs a lot of works }\end{array}$ & 3.41 & 1.00 & 16 & Medium \\
\hline 21) & $\begin{array}{l}\text { Do you think the main reason behind not moving to IPv6 yet is the reluctance of Jordanian } \\
\text { firms as it needs a lot cost }\end{array}$ & 3.46 & 0.98 & 11 & Medium \\
\hline 22) & $\begin{array}{l}\text { Can you collaborate and communicate with the glob if we don't activate the IPv6 in Kingdom } \\
\text { of Jordan? }\end{array}$ & 3.15 & 1.02 & 25 & Medium \\
\hline
\end{tabular}




\begin{tabular}{|c|c|c|c|c|c|}
\hline 23) & $\begin{array}{l}\text { Do you thing IT sectors development in Jordan are in parallel with the development of IT } \\
\text { sectors in other countries in term of using IPv6 }\end{array}$ & 2.84 & 1.04 & 32 & Medium \\
\hline 24) & $\begin{array}{l}\text { Do you think Ministry of IT and communication plays essential role in activating IPv6 in } \\
\text { kingdom of Jordan }\end{array}$ & 3.69 & 0.97 & 4 & High \\
\hline 25) & Will you face any difficulties in moving from IPv4 to IPv6? & 3.45 & 0.85 & 13 & Medium \\
\hline 26) & Do you think using IPv6 will require new security policies and procedures? & 3.66 & 0.82 & 6 & Medium \\
\hline 27) & Do you prefer new services to be offered on IPv6? & 3.41 & 0.88 & 16 & Medium \\
\hline 28) & Do you think Jordan economic is behind not having IPv6 in all state of kingdom of Jordan & 3.51 & 1.16 & 8 & Medium \\
\hline 29) & Do you have any experience or even knowledge of IPv6 services? & 3.30 & 0.96 & 21 & Medium \\
\hline 30) & $\begin{array}{l}\text { Do you think Telecommunication Sectors in Jordan is advanced in comparison with other } \\
\text { technological countries? }\end{array}$ & 2.99 & 1.04 & 29 & Medium \\
\hline
\end{tabular}

Most notably, Question number (18), which states " Do you have the willingness to participate in any IPv6 workshops in Kingdom of Jordan?" got the highest arithmetic mean and high degree. Then, Question number (12) got the second place which achieves a mean (3.73) and high degree, which states: "Do you think ISPs play essential roles in not disseminating Ipv6 in Kingdom of Jordan?". The lowest arithmetic mean was for Question number (17), which states, "Are you aware of companies use Ipv6? ", the arithmetic mean was (2.70) with moderate degree.

In order to check the hypotheses, the average and standard deviations of using IPv6 in Jordan were used by taking into account the three main factors (gender, educational qualification, and place of residence,). The analysis of variance (ANOVA) was utilized in this study to compare the means of responses given by male and female, city, etc. respondents in order to explore differences [8].

TABLE III. AVERAGES AND STANDARD DEVIATIONS OF USING OF IPV6 UPON THREE STUDIED FACTORS

\begin{tabular}{|l|l|l|l|}
\hline Variable & Category & SMA & $\begin{array}{l}\text { The standard } \\
\text { deviation }\end{array}$ \\
\hline \multirow{2}{*}{ Gender } & Male & 3.39 & 0.53 \\
\cline { 2 - 4 } & Female & 3.26 & 0.42 \\
\hline \multirow{2}{*}{$\begin{array}{l}\text { Place of } \\
\text { residence }\end{array}$} & City & 3.27 & 0.49 \\
\cline { 2 - 4 } education & Village & 3.49 & 0.38 \\
\cline { 2 - 4 } & Diploma & 3.28 & 0.44 \\
\cline { 2 - 4 } & Bachelor & 3.32 & 0.55 \\
\cline { 2 - 4 } & Master & 3.36 & 0.35 \\
\hline
\end{tabular}

As shown in table 3 and 4 , there were no statistically significant differences at the level of significance $(\alpha \leq 0.05)$ in the level of using the IPv6 in the Hashemite Kingdom of Jordan in corresponding with gender and educational qualification factors ( i.e., F value doesn't reach to the level of statistical significance (0.05). Therefore, hypotheses 1 and 2 are rejected.

From table 3 and 4 , there were statistically significant differences at the level of significance $(\alpha \leq 0.05)$ in the level of using the IPv6 in the Hashemite Kingdom of Jordan in corresponding with place of residence factor. Village arithmetic mean was 3.49, while the arithmetic mean for city factor was 3.27. The value of (f) for Place of residence factor was 4.605 at the level of statistical significance (0.03), which is less than 0.05 . Therefore hypothesis number 3 is accepted.
TABLE IV. STATISTICAL SigNIFICANT COMPARISON IN TERMS OF THREE FACTORS

\begin{tabular}{|c|c|c|c|c|c|}
\hline 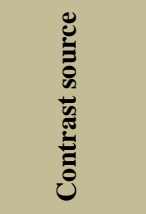 & 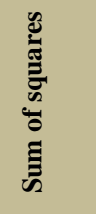 & 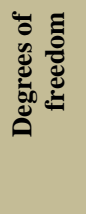 & 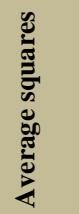 & 工x & 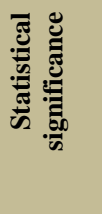 \\
\hline Gender & 0.316 & 1 & 0.316 & 1.439 & 0.233 \\
\hline $\begin{array}{r}\text { Place of } \\
\text { residence }\end{array}$ & 1.010 & 1 & 1.010 & 4.605 & 0.034 \\
\hline educational & 0.373 & 2 & 0.186 & 0.850 & 0.431 \\
\hline The error & 20.832 & 95 & 0.21 & & \\
\hline $\begin{array}{r}\text { Total } \\
\text { debugger }\end{array}$ & 22.393 & 99 & & & \\
\hline
\end{tabular}

\section{CONCLUSION AND FUTURE WORKS}

The IPv6 as a protocol and technologies starts to march out across the world because of its exaggerated addressing space. Therefore, Internet addresses with IPv6 will meet the internet demand for the expected future, unlike the existing and exhausted IPv4 address space. As a result, the world has already start adopting IPv6 addresses, for instance Google and Facebook officially adopted IPv6 since 2012. Organizations worldwide are tirelessly planning for the migration. However, some organizations are slower than others to make the switch. Even though, many private and government bodies are moving to IPv6 and all major modern organizations have made the switch, still few challenges has to be addressed in order for governments to move forward towards IPv6 adoption. In this study, there is emphasizes on the need to migrate from IPv4 to IPv6 and investigate the factors that are slowing the migration process in Jordan. The conducted study reveals that Jordan people who live in villages are not very aware of the new internet protocol advantages compared to those lived in cities. This clearly indicates that the awareness programs for IPv6 among Jordanian people are targeted programs for certain sectors from the industry such as the telecommunication players who in turns keeping the granted IPv6 blocks until their allocated IPv4 addresses are sold out.

\section{REFERENCES}

[1] Jari Arkko et al., "The Seven Stages of IPv6 Adoption", IETF 74 IPv6 PANEL, IETF Journal, June 2009, Volume 5, Issue 1, pp 14-17.

[2] NRO Statistics: https://www.nro.net/, (accessed 10/05/2016) 
[3] Jakub Czyz et al., "Measuring IPv6 adoption", ACM SIGCOMM Computer Communication Review - SIGCOMM'14, Volume 44 Issue 4, October 2014, Pages 87-98, ACM New York, NY, USA

[4] Kalwar, S.; Bohra, N.; Memon, A.A., "A survey of transition mechanisms from IPv4 to IPv6 - Simulated test bed and analysis," IEEE 2015 Third International Conference on Digital Information, Networking, and Wireless Communications (DINWC), pp.30-34, 3-5 Feb. 2015

[5] Oxley, A., "Issues affecting the adoption of IPv6," IEEE 2014 International Conference on Computer and Information Sciences (ICCOINS), pp.1-6, 3-5 June 2014
[6] APNIC, Access online on June 2016. Available https://www.apnic.net/.

[7] Santos, J. R. (1999). Cronbach's Alpha: A tool for assessing the reliability of scales. Journal of Extension [On-line], 37(2). Available at: http://www.joe.org/joe/1999april/tt3.html

[8] Larson, M. G. (2008). Analysis of variance. Circulation, 117(1), 115121.

[9] http://ipv6-test.com/, Access online on June 2016. 